\title{
O percurso do menino-griot: das despedidas à aprendizagem ${ }^{1}$
}

\section{Adriana Elisabete Bayer*}

\begin{abstract}
Resumo: Este estudo busca explicitar, em Bom dia Abstract: This study seeks to explain the interrelation camaradas (2001), de Ondjaki, a inter-relação entre a between the identity building both of the protagonist construção da identidade tanto da personagem character and of the ritualistic practices in Good protagonista como da narrativa e as práticas Morning Comrades (Bom dia camaradas, 2001), by ritualísticas. Valendo-se dos estudos de Paul Ricoeur Ondjaki. Relying on Paul Ricoeur's studies about sobre identidade e dos termos daí resultantes - identity and the terms resulting from there "mesmidade" e "ipseidade" - objetiva comprovar que "sameness" and "selfhood" - it intends to verify that as práticas ritualísticas presentificam os meios através the ritualistic practices presentify the means through dos quais ocorrem as aprendizagens e, ao mesmo which the apprenticeships occur and that they tempo em que impulsiona as ações do(s) jovem(ns), simultaneously propel the young(s) actions and denote denota a emergência e a renovação do patrimônio the emergency and the renewal of the Angola's cultural cultural de Angola. patrimony.
\end{abstract}

Palavras-chave: Literatura angolana; Ondjaki; Keywords: Angolan literature; Ondjaki; Identity; Identidade; Juventude. Youth.

Às vezes numa pequena coisa pode-se encontrar todas as coisas grandes da vida, não é preciso explicar muito, basta olhar...

ONDJAKI

Bom dia camaradas

Cúmplice de um novo tempo cuja instauração manifesta transformações políticoeconômicas e sociais em Angola pós-colonial, no quartel compreendido entre o final de 1980 e o início de 1990, a voz de um jovem materializa o romance Bom dia camaradas, de Ondjaki ${ }^{2}$. Ele, que agora ocupa a posição antes destinada ao griot nas narrativas orais, carece da proveitosa experiência de vida, marca dos ancestrais contadores de história. Se essa denota longos anos vividos e por isso confere autoridade para narrar, o narrador-menino perfaz o seu caminho dele coletando rico material, que transforma em tema esteticamente elaborado.

\footnotetext{
${ }^{1}$ Excerto de dissertação de mestrado, intitulada Pepetela e Ondjaki: com a juventude, a palavra faz o sonho.

* Graduada em Letras pela UNISINOS; Mestre e Doutoranda em Teoria da Literatura pela PUCRS. E-mail: adribayer@yahoo.com.br.

${ }^{2}$ ONDJAKI. Bom dia camaradas. Rio de Janeiro: Agir, 2006. Todas as citações empregadas neste estudo serão retiradas dessa edição.
} 
Valendo-me dos termos de RICOEUR ${ }^{3}$ (1991), compreendo a narrativa desse jovem como uma intriga que abarca o final de um ano letivo, por conseguinte, os últimos momentos vividos ao lado dos professores cubanos e dos colegas de classe. Esse período da vida do rapaz está articulado ao contexto histórico-social expresso pelo acordo de paz entre correntes partidárias oposicionistas, que culmina no fim do monopartidarismo em Angola. Assim, início, meio e fim da narrativa trazem um rito de passagem que indica o afastamento da infância do menino-narrador para outra margem, aquela vizinha do mundo adulto. Nesse ínterim, há ainda uma série de ritos que cooperam para a verossimilhança do rito de passagem e que compõem tanto a identidade narrativa quanto a identidade pessoal da personagem e da comunidade.

A fim de responder a pergunta que se coloca para a investigação da identidade pessoal, ou seja, "quem fez tal ação", segundo afirmativa de RICOEUR (1991), volto-me para a análise da trajetória do narrador-menino. Angolano, sem idade nem nome precisos na narrativa, ele é o jovem que suporta contrariedades provocadas por diversos afastamentos. "Isso das despedidas, eu não gosto nada" (p.109), diz o rapaz que está apreensivo, pois o final do ano letivo sinaliza a separação dos colegas e ao regresso dos professores a Cuba.

Desses afastamentos, apenas aquele que prevê a desintegração do grupo se dá de forma paulatina, visto que ele já é esperado com o término das aulas. Os cubanos, por sua vez, anunciam sua partida abruptamente. No entanto, também a repentina morte do camarada António deixa marcas significativas na história de vida do garoto.

Portanto, Bom dia camaradas é a narrativa presentificada pela voz de seu protagonista. O menino conta experiências vividas em um determinado período de sua vida. Entretanto, não se pode afirmar que ele seja o mesmo indivíduo daquele momento, pois o distanciamento temporal que há entre atos praticados no passado e o presente da narração permite avaliar e a reelaborar ações antes desempenhadas. Exemplifico a constatação com a frase "fui fazer os deveres, como dizíamos antigamente" (p.25). Ela denota o hiato temporal entre o praticante da ação e aquele que a registra no papel. Por isso, RICOEUR (1991) fala em identidade narrativa, uma vez que a dinamicidade imanente à estrutura temporal é a própria constituição da intriga e, por conseguinte, a dialética da mesmidade e da ipseidade está a ela relacionada.

Para resgatar as lembranças, o narrador apóia-se na memória sensorial, principalmente na olfativa. É por meio dos cheiros que ele reencontra António e seu odor de cozinha -

\footnotetext{
${ }^{3}$ A análise identitária tanto da narrativa como das personagens do romance Bom dia camaradas baseia-se em pesquisas de RICOEUR, Paul. A identidade pessoal e a identidade narrativa; O si e a identidade narrativa. In: RICOEUR, Paul. O si-mesmo como um outro. Campinas: Papirus, 1991.
} 
"todos os dias ele tinha o mesmo cheiro" (p.18) —; os colegas da escola e o "cheiro de catinga" (p.30); os professores cubanos e a última vez em que os viu em seu apartamento com “cheiro de mofo" (p.126); Luanda e seu "cheiro quente" (p.99). A ativação do olfato associase aos outros sentidos que, juntos, contribuem para o narrador refazer o percurso que o tornou um contador de histórias. Dessa forma, com o propósito de pontuar essa trajetória, destacando sua importância para a formação identitária da personagem, inicio o exame pelo espaço social, representado pela escola, ou seja, pela interação entre os agentes, professores cubanos e alunos.

A escola é o espaço no qual sucede a inter-relação entre os jovens oriundos da classe média luandense, excetuando dessa condição o menino Murtala e os professores, com relevo para os cubanos. Esses profissionais, que vêm de um país distante, contribuem para a formação intelectual e afetiva dos jovens angolanos. Investigando a relação entre professores e alunos com auxílio da teoria de RICOEUR (1991), denomino situação concordante ao relato da metodologia utilizada pelos mestres, bem como o comportamento desses indivíduos.

A situação concordante, ao mesmo tempo em que se instaura mediante a sucessão de fatos, materializa uma prática ritualística. A aula, portanto, é um rito, ou seja, "uma repetição ininterrupta de gestos inaugurados por outros" (ELIADE, 1969, p.19). Nesse contexto, os professores são os seres através de cuja exemplaridade os alunos vão se orientar; não simplesmente para imitá-los, mas para elaborar novos significados para suas condutas. O excerto abaixo exemplifica o procedimento utilizado em sala de aula:

\footnotetext{
Mas não era só do professor Ángel e da professora María. Nós gostávamos de todos os professores cubanos, também porque com eles as aulas começaram a ser diferentes. Os professores escolhiam dois monitores por disciplina, o que primeiro gostámos porque era assim uma espécie de segundo cargo (por causa do delegado da turma), mas depois não gostámos muito porque para ser monitor 'había que ayudar a los compañeros menos capacitados' - como diziam os camaradas professores, e tinha que se saber tudo sobre a disciplina e não se podia tirar menos que 18 (p. 22).
}

Segundo a percepção do menino-narrador, que assume a representação de si e dos colegas, a diferença da metodologia dos cubanos ampara-se na distribuição de cargos entre os alunos. Portanto, eles não são tratados como indivíduos eximidos de responsabilidades. Em contrapartida, a reputação exige a disciplina para o estudo, pois faz-se necessário auxiliar os colegas com dificuldades na aprendizagem. Ora, na aula — ou prática ritualística — reside a formação de um hábito que passa a compor um traço do caráter dos alunos. No entanto, ressalto que a solidariedade se consolida como propriedade do caráter porque há a identificação com os mestres, pois suas atitudes e as de outros cubanos atuantes em áreas diversificadas são modelares para os jovens: 
- Pois, mas eles como são militares têm sempre essa coisa de combater. Mesmo assim eu acho que eles são corajosos...

- Yá... - eu olhava o sol já quase escondido.

- Já viste o que é, vir para um país que não é o deles, vir dar aulas ainda vá que não vá, mas aqueles que vão pra frente do combate... quantos angolanos é que tu conheces que iam para Cuba lutar numa guerra cubana?

- Eu acho que eles são muito corajosos... Nunca ouvi nenhuma estória de cubano que estivesse a fugir do combate... - a Romina parecia bem informada, eu não quis ficar atrás.

- Nem pensar, até bem pelo contrário, toda gente sabe que eles são bem corajosos... (p. 77).

A preocupação com o outro, manifesta nas ações dos cubanos, resulta em paradigma a ser perseguido pelos jovens e, como diz Ángel, "num país em reconstrução era preciso muita disciplina" (p.21). A firmeza exigida pelo professor não se aparta da afeição que ele e os outros mestres dispensam aos jovens. Por isso, os cubanos são convidados a partilharem reuniões festivas em casa de Romina, estreitando vínculos das relações exercidas no ambiente público com aquelas do privado:

a mãe da Ró, que é muito atenta, trouxe dois pires com compota de morango, um para cada um dos camaradas professores. Era ver aquelas caras: olhavam para o doce a rir, comiam uma colherada, ficavam a chupar o doce na boca, demoravam, olhavam um para o outro, ele e a mulher, a sorrirem por causa da compota de morango, eu acho que aquela era uma cena muito bonita (p.110).

A simplicidade é característica marcante desses docentes que vieram a Angola com o objetivo de auxiliar na reconstrução do país e, ao mesmo tempo, divulgar o projeto socialista. O salário recebido pelo trabalho não lhes permite viver sequer com conforto, nem consumir alimentos considerados supérfluos para o minguado orçamento familiar, por isso eles se regalam com compota de morango na casa da aluna, provocando enternecimento, traduzido pelo olhar do menino-narrador. Em visita à morada dos mestres, os alunos respiram com dificuldades, conseqüência do forte "cheiro a mofo" (p. 125). Ademais, as condições do chá oferecido pela professora María denota o estado de penúria vivido pelos cubanos. A indagação vem do protagonista:

Mas eu pergunto-me: aquilo era chá? Quer dizer, um pacote de chá dividido por duas chávenas, quatro copos e um pires, ainda é chá? Logo eu que fui o último, tive que imaginar que aquilo era sumo de açúcar, e depois ainda tive que pensar que não era preciso imaginar esse sumo porque aquilo era mesmo sumo de açúcar (p. 125)

Os jovens para eles são "las flores de la Humanidad" (p.113), aqueles sobre quem recai a responsabilidade do futuro do país. Assim, em seu discurso final, Ángel diz, "volvemos alegres a nuestra patria sabiendo que Angola tiene jóvenes, en su mayoría, tan empeñados en la causa revolucionaria, porque la causa revolucionaria, sobretodo, es el progreso" (p. 113). Essa é a despedida dos cubanos e com ela instala-se a situação 
discordante, ou o imprevisto, com o qual os alunos não contavam. Todavia, o conteúdo da mensagem se alia ao procedimento das aulas ministradas e à retidão do caráter dos professores. Nesse sentido, discurso e práxis contribuem para a formação identitária dos jovens, exibida pela ipseidade "do outro e com o outro", estabelecendo a síntese do heterogêneo. O resultado da correlação entre alunos e professores fica expresso nas palavras ditas por Petra, reveladas pelo protagonista-narrador :

Nós agradecíamos tudo o que os camaradas professores pessoalmente tinham feito por Angola, desde os operários, os soldados, os médicos e os professores, que Angola estava agradecida e que íamos sempre ser irmãos, os angolanos e os cubanos, etc., etc., etc. (p.126).

A tristeza manifesta pelo menino-narrador, envolto no "cheiro de despedida", converte-se em esperança: "Um pingo de chuva, sozinho, caiu-me na cabeça, nessa que foi a última vez que vimos aqueles camaradas professores cubanos” (p. 128). A partida dos cubanos está vinculada ao acordo promovido entre o MPLA e os partidos oposicionistas. O solitário pingo de chuva metaforiza a possibilidade de paz que chega ao país, após sucessivos anos de guerra civil. O período vivido em companhia dos professores cubanos é de extrema relevância para o menino, que o guardou na memória para divulgá-lo no futuro, atendendo assim aos apelos de mestre Ángel, para quem "la lucha continua" e a caneta é "a arma do pioneiro" (p. 30).

Por isso, no caminho percorrido, o menino coleta material que fará dele um griot da modernidade. Para ele, ainda aluno, a escola é o espaço da socialização por excelência. Dessa maneira, as práticas ritualísticas, presentificadas nas aulas promovidas pelos professores cubanos, oferecem possibilidade de o jovem (re)conhecer e se identificar com valores transmitidos. Se a solidariedade tem primazia nesses valores, ela corresponde aos anseios tanto do jovem quanto da comunidade na qual ele se insere. Assim, o aspecto ético faz com que a identidade pessoal do rapaz se revele em processo, ou como diz RICOEUR (1991), em constante "manutenção do si".

Outras situações de aprendizagem contribuem para o processo de mutabilidade identitário, proporcionando o recobrimento do idem pelo ipse. Elas também ocorrem na escola e apresentam as características dos ritos. Por exemplo, as brincadeiras como aquela do Caixão Vazio que no amálgama do medo real com o imaginário surgem novas maneiras de lidar com a violência imanente à realidade circundante. $\mathrm{O}$ aspecto lúdico também se apresenta em circunstância oficial quando se referencia à pátria e a seus heróis. Obedecendo aos preceitos ritualísticos, os jovens se dirigem ao Largo, a fim de comemorar o Dia Internacional do Trabalhador: 
Estávamos todos direitinhos, em sentido, passaram revista aos lenços, quem não tinha lenço podia voltar pra casa, aquilo era o desfile do $1^{\circ}$ de maio, dia internacional do trabalhador, não admitia criança sem o fardamento completo. Começámos: 'Ó pátria nunca mais esqueceremos/os heróis do 4 de fevereiro...'(p. 82).

A solenidade exigida pela ocasião resgata e homenageia os heróis que lutaram pela libertação do país e, concomitante, reitera a importância da continuidade da luta expressa nas palavras de ordem: "um só povo / uma só nação"; "a luta continua"; "a vitória é certa"; "o MPLA é o povo / o povo é o MPLA" (p. 84). Para os jovens, no entanto, a cerimônia é motivo de festa: "aquilo tava cheio de cores e muita agitação, também porque o camarada do microfone é que ficava a aquecer as pessoas” (p. 83). É pelo ludismo que se dá a apreensão do valor da luta e da união do povo: "uns já tavam a ficar roucos, mas nós adorávamos aquela hora de ficar a responder assim aos berros" (p. 84). Dessa forma, a descrição do ritual, com a harmonia subjacente, noticiada através do olhar terno do narrador, compreende a situação concordante. Essa é rompida quando se instaura o abatimento materializado na certeza de que "quando as despedidas começam elas nunca mais param” (p.93). Em diálogo com a colega Romina o narrador-menino desabafa:

Eu não gosto de despedidas, sabes... Hoje estávamos ali no Largo $1^{\circ}$ de Maio e depois do comício comecei a pensar nisso...

A pensar em quê?

Que as coisas sempre acabam, Ró.

Mas tás a falar de quê?

De tudo... Por exemplo aquela alegria, aquela gritaria ali com o hino e as palavras de ordem, tudo isso acaba, né, as pessoas vão para casa, separam-se...

Não fiques assim.

Não... não é isso... Vês, agora temos mais algum tempo de aulas, depois já são as frequências finais, depois as pessoas vão de férias, depois há pessoas que não voltam, mudam de turma, é sempre assim, Ró, as acabam por se separar... (p. 92-92).

Afinal, o término do ano letivo aproxima-se, trazendo consigo as hesitações em relação ao futuro. A separação do grupo de colegas e dos professores cubanos é motivo gerador de conflitos para o jovem que vive um período acentuado pelo amplo processo de socialização, que há entre o final da infância e o ingresso no mundo adulto. Na verdade, para o rapaz, "isso de ser mais velho deve masé [sic] dar muito trabalho" (p. 95). Nessa etapa transitória, os ritos auxiliam na construção da identidade e, conseqüentemente, na consolidação de papéis sociais a serem exercidos.

$\mathrm{O}$ ano letivo, compreendido como um rito de passagem, é encerrado pelo grupo de colegas com desenhos e pinturas nas paredes e portas da escola e com a queima dos cadernos e livros didáticos. Conforme o menino-narrador: "o Bruno ainda gozou: 'os meninos à volta da fogueira..." (p. 133). Eles não estão em volta das chamas para ouvir histórias narradas 
pelo velho-griot, mas para incendiar ensinamentos que renascerão no período seguinte, mediados por outros mestres e outros colegas, pois um novo grupo se formará. Por outro lado, as gravuras em paredes e portas permanecerão, indicando e perenizando a passagem desse grupo, que se singulariza pelo tempo convivido e pelas ações conjuntas.

Dessa forma, em termos de identidade pessoal, a interação grupal modifica comportamentos. O impedimento de cristalizações atua no caráter dos envolvidos, pois ao se identificar - ou, o contrário, não se identificar - com o outro eles não são os mesmos indivíduos que juntos iniciaram as aulas. Em termos de identidade narrativa, as ações empreendidas pelo grupo materializam a situação concordante dilacerada pelo afastamento, sinonimizando a situação discordante. Em outras palavras, o período em que o meninonarrador convive com os colegas compreende um rito de passagem, no qual o obstáculo maior a ser vencido está na separação desse grupo. A síntese do heterogêneo virá somente com a narração efetuada pelo menino-griot que, ao desatar os fios urdidores da memória, reelabora as despedidas, dispensando-lhes novos significados.

Se as situações de aprendizagem ocorridas no âmbito escolar são práticas ritualísticas por meio da quais as personagens jovens amadurecem, a arte de narrar concretiza-se por um outro ritual, cujo ato de experienciação concorre para formar a identidade. Logo, para o menino-narrador que procura assunto a ser transformado em matéria narrativa fica, outrossim, a desolação: “'Que irritante!', pensei, assim nunca mais se sabia de nada para contar, alguns iam começar já a dizer que era tudo invenção e o Caixão Vazio não tinha estado na minha escola" (p. 91).

O menino necessita do apoio da veracidade dos fatos para lograr a credibilidade dos ouvintes, pois não possui a autoridade conferida aos velhos griots. Além disso, a curta experiência de vida não permite que tenha a prodigiosa memória dos ancestrais. Portanto, em vez de contador de missossos ele se faz contador de makas. Essa forma narrativa, segundo Laura C. Padilha, "relatava um acontecimento representado como vivido, ou pelo contador, ou por alguém de sua intimidade, ou por pessoas que ouviu falar" (1995, p. 19). É nesse sentido que perscrutando tudo que vê, ouve, cheira, toca ou degusta; ele converte em makas ${ }^{4}$ ou seja, formas narrativas ficcionalizadas, mas amparadas no vivido.

A confiança da audiência no contador também depende da coerência da narrativa. E, por conseguinte, a lógica subordina-se à extensão dos fatos narrados. Por não respeitar as

\footnotetext{
${ }^{4}$ Embora em Bom dia camaradas o vocábulo 'maka' seja utilizado pelo menino narrador com significado de 'problema' ou 'assunto' - conforme página 59 - aqui emprego no sentido de "indicar um tipo de narrativa oral”, segundo Laura C. Padilha (1995, p. 19).
} 
regras que vêm de tempos longínquos, já que relembrando PADILHA, as narrativas orais apresentam estrutura linear e têm "um tempo-espaço discursivo breve, o que faz com que se chegue em um ritmo acelerado ao desfecho" (1995, p. 24), o narrador questiona a contação de Murtala, de quem "era sempre de desconfiar, porque sempre tinha a mania de aumentar muito as estórias, quer dizer, toda a gente que eu conheço aqui em Luanda aumenta estórias, mas o Murtala, como diz Petra, era abusivo" (p. 81).

Em um continente que tem, de acordo com as palavras de Laura C. Padilha, "na milenar arte de contar sua base de sustentação, [...] a oralidade é o alicerce sobre o qual se construiu o edifício da cultura nacional angolana nos moldes como hoje se identifica" (1995, p. 16-17). Espaço que mantém uma relação metonímica com o país, "Luanda, em sua multiplicidade é também, e talvez mesmo por suas contradições a imagem símbolo de Angola" (MACEDO, 2006, p. 177). Portanto, o gosto pela contação faz parte do cotidiano de seus habitantes, pois está emaranhado ao próprio tecido social. Por sua vez, essa característica manifesta-se na narrativa ficcional. Daí a constatação do menino-narrador: “ê!, aqui em Luanda, não se pode duvidar das estórias, há muita coisa que pode acontecer e há muita coisa que, se não pode, arranja-se uma maneira de ela acontecer” (p.108).

Eis os motivos para a modelação de makas e também de missossos na modernidade, na medida em que aquelas, conforme PADILHA, "seriam a ficcionalização de uma história tomada como verdadeira, razão pela qual tinham um fim utilitário evidente" e esses produtos “apenas do imaginário, algo não percebido no real empírico” (1995, p. 19).

No espaço coletivo, concretizado pela escola e pela sociedade, o menino, ao se relacionar com colegas e professores, vive situações que particularizam sua existência, conseqüentemente, elas contribuem para a (trans)formação de sua identidade. Ele, como "um mesmo", é o menino angolano; no entanto, é "um outro", ao passo que se modifica no decorrer do convívio. A dimensão ética subjacente à jornada presentifica-se no ato de narrar. O meio social estimula-o a converter as experiências vividas em matéria narrativa, tornando essa prática um hábito. Por isso, ele se sente frustrado quando o calor excessivo de Luanda interfere, impedindo o pronunciamento de contadores e ouvintes: "na escola, àquela hora, fazia sempre muito calor, dava sono. Isso só me chateava porque em vez de ficarem a contar estórias, alguns colegas ficavam aquele tempo a dormir" (p. 43). Todavia, não é somente a relação sucedida no espaço plural da escola que importa à construção identitária do jovem e ao caminho percorrido pelo aprendiz de griot; para isso concorrem também as relações mediadas no espaço privado de sua casa. 
Na casa está o camarada António e seu eterno odor de cozinha: "todos os dias ele tinha o mesmo cheiro, mesmo quando tomava banho" (p. 18). António é o velho que já não cumpre as atribuições concedidas aos anciãos do "antigamente". A autoridade que detinha sobre a palavra está perdida, pois passa a ser constantemente refutada pelo moço, na narrativa em análise, o menino-narrador. É sua a voz manifestada para reclamar a importância de um novo tempo, ignorada pelo velho: “- Não é isso, António - eu levantava-me do banco. - Não eram angolanos que mandavam no país, eram portugueses... E isso não pode ser...” (p. 18). Preso ao passado colonial, quando "tinha sempre pão na loja" (p.18), o cozinheiro não percebe o mérito das mudanças ocorridas no país com o advento da independência.

Relegado à cozinha - espaço apartado da ala social da casa - , o velho cuida da organização desse lugar e da transmutação alquímica dos alimentos, garantia da ordem do cotidiano familiar. O deslocamento experimentado pelo velho, no entanto, não o isola do jovem. Esse procura naquele o afeto, a amizade, a companhia. Estar junto ao camarada António significa para o menino observar seus gestos, dialogar, sentir os seus "cheiros". Assim, em outro tempo, quando colocar a sua história na folha estática do papel, é pela ativação dos sentidos que a memória será despertada:

'Bom dia, menino!', disse o camarada António quando eu já estava a acabar o matabicho. 'Bom dia, camarada António, tudo bem?', enquanto ele começava a arrumar melhor os copos, mudava os pratos de sítio, abria a geleira e espreitava, abria a janela da cozinha, tudo só por hábito, não é que aqueles gestos fossem para alguma coisa, não sei se já repararam que os mais velhos fazem muito isso (p. 51).

O comentário do narrador, na verdade, refere ao ritual efetuado por António e pelos "mais velhos". Em meio à repetição automatizada de atos, o ritual apresenta um caráter de permanência, que, por sua vez, incide sobre a vida do jovem na fase de aprendizado. Ao observar o outro, ele reflete sobre si mesmo e sobre a realidade circundante. Inserido, portanto, nas práticas ritualísticas, o narrador estabelece outros contatos, como com a guerra, por exemplo.

Aqui novamente há evidência do afastamento do velho, que com sua voz griótica difundia a "sabedoria ancestral", conforme PADILHA (1995). Agora, os indivíduos não se reúnem à volta da fogueira a fim de ouvir histórias. Eles se agrupam em torno do rádio para a audição e creditam à voz do locutor a veracidade dos fatos narrados. O ritual da audição é uma circunstância bastante significativa à família do narrador:

A casa ficava mais barulhenta, mais o barulho do rádio na sala para ouvir as notícias, mais o rádio do camarada António ligado na cozinha, mais a minha irmã caçula que queria contar tudo o que se tinha passado na escola nessa manhã. Ela sabia que tinha que se despachar 
porque quando fosse uma hora em ponto ia ter que parar o relato para deixar os pais ouvirem as notícias (p. 27).

Se os pais estabelecem o ritual de audição com o propósito de saber as últimas ocorrências, para o menino esse também é um momento de aprendizagem. A situação presentifica a interação com o outro, sucedida através das notícias divulgadas. Dessa forma, manifesta-se o impulso dialético, que faz da identidade algo relacional, ou seja, construída "no outro e com outro", segundo afirmativa de RICOEUR (1991). Essa constatação parte do relato do jovem, para quem durante a audição:

Também se aprendia muita coisa, porque a propósito disso, por exemplo, do ANC, é que o meu pai nos explicou quem era o camarada Nelson Mandela, e eu fiquei a saber que havia um país chamado África do Sul onde as pessoas negras tinham que ir para casa quando tocava a campainha às seis da tarde, que elas não podiam andar no machimbombo com outras pessoas que não fossem negras também [...]. Foi também assim que percebi porquê que os sulafricanos eram nossos inimigos, e que o facto de nós lutarmos contra os sul-africanos significava que nós estávamos a lutar contra 'alguns' sul-africanos, porque de certeza que essas pessoas negras que tinham um machimbombo especial para elas não eram nossas inimigas. Então também percebi que, num país, uma coisa é o governo, outra coisa é o povo (p. 28).

O conteúdo da fala do narrador vem ao encontro da teoria de RICOEUR (1991) quando o filósofo francês reporta à relevância das tomadas de decisão para desagregar essencialismos, constitutivos da mesmidade. Explicando de outra maneira, o jovem se identifica com as ações do líder Nelson Mandela e com os negros sul-africanos permanentemente expostos a situações aviltantes. A identificação dá-se porque também o narrador vive em um país no qual os negros, em sua maioria, foram alvos do segregacionismo. A consciência desse fato está expressa no diálogo em que o menino mantém com António: “- As pessoas não ganhavam um salário justo, quem fosse negro não podia ser director, por exemplo..." (p.18). Nesse sentido, o momento destinado à audição de notícias materializa um ritual através do qual ocorre o aprendizado norteado pela dimensão ética. Em contrapartida, as notícias ouvidas são transformadas em matéria ficcional pelo menino, a cuja aguçada percepção, nada escapa.

O ritual também se manifesta na maneira como o narrador apreende os dados da realidade circundante. As sensações reincidem ao longo da narrativa. Tantas vezes repetidas, elas compõem a malha da memória em cujos fios estão o cheiro das noites e das manhãs de Luanda; da catinga dos colegas de classe; da cozinha do camarada António. O cheiro permanece na lembrança do dia em que foi à praia com Dada: "há quem não goste, mas eu acho que o peixe seco cheira muito bem, parece sumo concentrado de mar" (p. 62). O olhar 
perspicaz também colabora para formar o mosaico composto de sensações: "vocês sabiam que o abacateiro também se espreguiça?" (p. 79).

A permanência, subjacente ao ritual, está nos fios que atam o presente da narração ao passado, aquele vivido pelo menino, quando, afinal, no país houve um aceno à necessária paz entre os angolanos, coincidindo com o dia da morte do camarada António . A purificação desse tempo então presente vem simbolizada pela água que cai em forma de chuva:

\begin{abstract}
Ao ver tanta água, lembrei-me das redacções que fazíamos sobre a chuva, o solo, a importância da água. Uma camarada professora que tinha a mania que era poeta dizia que a água é que traz todo aquele cheiro que a terra cheira depois de chover, a água é que faz crescer novas coisas na terra, embora também alimente as raízes dela, a água faz 'eclodir um novo ciclo', enfim, ela queria dizer que a água faz o chão dar folhas novas. Então pensei: 'Epá... E se chovesse aqui em Angola toda...? Depois sorri. Sorri só (p. 137).
\end{abstract}

Ao mesmo tempo em que a água representa a vida, fertilizando a terra, metaforicamente, ela traz consigo o incentivo ao (re)nascimento de outros paradigmas, mediado por novas relações, tanto no âmbito individual quanto no coletivo. No presente, a intensa chuva parece trazer a paz tão esperada pelos angolanos. No entanto, o passado não está omitido, pois ele constitui a história, sem a qual não há futuro.

Em Bom dia camaradas, ao despertar das sensações, em um contínuo desentrelaçamento do tecido memorialístico, cabe o papel de recuperar o pretérito, reconstruindo a identidade pessoal e, conseqüentemente, a narrativa, pois elas estão imbricadas. No entanto, diferente das narrativas oriundas da tradição oral, o menino assume o comando da narração, pois o velho, na figura de António, perdeu sua força ao ficar atado a um período histórico, no qual os angolanos não tinham rosto nem voz. Se "a água faz o chão dar folhas novas" (p. 137), concerne ao jovem a reinvenção da história de seu país.

\title{
Referências
}

ELIADE, Mircea. O mito do eterno retorno. Lisboa: Edições 70, 1969.

MACEDO, Tânia. Luanda: violência e escrita. In: CHAVES, Rita; MACEDO, Tânia (org.). Marcas da diferença: as literaturas africanas de língua portuguesa. São Paulo: Alameda, 2006.

ONDJAKI. Bom dia camaradas. Rio de Janeiro: Agir, 2006.

PADILHA, Laura Cavalcante. Entre a voz e a letra: o lugar da ancestralidade na ficção angolana do século XX. Niterói: EDUFF, 1995. 
RICOEUR, Paul. A identidade pessoal e a identidade narrativa; $\mathrm{O}$ si e a identidade narrativa. In: RICOEUR, Paul. O si-mesmo como um outro. Campinas: Papirus, 1991. 